\title{
ESTRANGEIRISMOS NA PAISAGEM LINGUÍSTICA DO CENTRO HISTÓRICO DE SÃO LUÍS
}

\author{
FOREIGNISMS IN THE LINGUISTIC LANDSCAPE OF THE HISTORIC CENTER \\ OF SÃO LUÍS
}

\author{
Recebido: 30/10/2021 Aprovado: 24/11/2021 Publicado: 22/12/2021
}

DOI: $10.18817 /$ rlj.v5i2.2697

\begin{abstract}
Denise Maia Pereira Laurindo ${ }^{1}$ Orcid ID: https://orcid.org/0000-0001-9071-8582 Gustavo Cardoso Silveira ${ }^{2}$ Orcid ID: https://orcid.org/0000-0002-6864-4860
\end{abstract}

\begin{abstract}
Resumo: O objetivo deste artigo é a análise randômica do estrangeirismo presente no Centro Histórico de São Luís do Maranhão, a fim de identificar a influência existente dentro do contexto sociocultural mencionado. A linguagem, seja ela verbal, visual ou verbo-visual, está presente em todos os ambientes em que nos colocamos e se tornam, por esse motivo, paisagens linguísticas que não se apresentam de maneira neutra ou arbitrária, mas se revestem de valores simbólicos. Como resultado dessa exposição, os sujeitos envolvidos na toponímia participam ativamente da construção e significação desse discurso presente nos espaços públicos (mesmo quando privados), interagindo na interpretação e aceitação das escolhas realizadas. A questão da escolha se faz relevante, pois ela interage por aquilo que poderia ter sido feito e não o foi, mostrando, assim, a possibilidade e construção de textos sombras (escolhas e possibilidades). Os resultados das análises mostram que as escolhas realizadas no contexto linguísticos tratam de contextos sócio-histórico e cultural, sendo assim, o contexto da escolha adquire significado a partir do produtor de contexto, o autor ou responsável pela produção linguística, que não é subserviente, mas ideologicamente e politicamente responsável.
\end{abstract}

Palavras-chave: Paisagem linguística. Toponímia. São Luís. Gênero do Discurso.

Abstract: The objective of this article is the random analysis of foreignism present in the Historical Center of São Luís do Maranhão, in order to identify the existing influence within the sociocultural context mentioned. Language, whether verbal, visual or verbal-visual, is present in all environments in which we place and become, for this reason, linguistic landscapes that do not present themselves in a neutral or arbitrary way, but are full of symbolic values. As a result of this exhibition, the subjects involved in toponymy actively participate in the construction and meaning of this discourse present in public spaces (even when private), interacting in the interpretation and acceptance of the choices made. The question of choice is relevant, because it interacts for what could have been done and was not, thus showing the possibility and construction of shadow texts (choices and possibilities). The results of the analyses show that the choices made in the linguistic context deal with socio-historical and cultural contexts, so the context of choice acquires meaning from the context producer, the author or responsible for linguistic production, which is not subservient, but ideologically and politically responsible.

Keywords: Linguistic landscape. Toponymy. St. Louis. Speech Genre.

\section{Introdução}

\begin{abstract}
1 Possui graduação em Letras pela Universidade Ceuma (2006). Pós graduada em Inglês como Língua Estrangeira pela Universidade Ceuma (2008). Pós graduada em Metodologia do Ensino Superior pela Universidade Federal do Maranhão (2009). É mestra em Linguística Aplicada (2017), área de concentração em Língua Materna e Línguas Estrangeiras. Doutoranda em Linguística Aplicada e Estudos da Linguagem (PUC-SP). Atualmente é professora do departamento de Letras da Universidade Estadual do Maranhão (UEMA). E-mail: maiadniz@hotmail.com
\end{abstract}

2 Doutorando em Linguística Aplicada e Estudos da Linguagem (PUC-SP); Mestre em Linguística Aplicada e Estudos da Linguagem (PUC-SP); Especialista em Língua Inglesa e Psicopedagogia; Professor de Línguas e Literaturas (português/inglês), Atuando há 18 anos com educação e formação de professores, possui experiência em mentoring e coaching de novos profissionais. Trabalhando com o desenvolvimento de projetos, com a apresentação de workshops e com cursos de formação. Examinador Cambridge ESOL. E-mail: gus.cs@uol.com.br 
Um dos aspectos peculiares que envolvem a cidade de São Luís, capital do estado do Maranhão, é o de ser uma cidade fundada por franceses, na tentativa de criar a França Equinocial. Posteriormente, a cidade foi invadida por holandeses até que, finalmente, foi colonizada por portugueses. Nesse contexto, repleto de singularidades históricas, indaga-se sobre a paisagem linguística nos espaços públicos e comerciais no centro histórico de São Luís, cidade que detém o título de Patrimônio Mundial da Humanidade, concedido pela Organização das Nações Unidas para a Educação, Ciência e a Cultura (UNESCO).

A linguagem, seja ela verbal, visual ou verbo-visual, está presente em todos os lugares, em placas, em anúncios, em fachadas comerciais, sinais e placas de trânsito e em telas, nas suas mais diversas formas, cores e texturas (BLOMMAERT, 2013), construindo paisagens que se referem à língua em espaços públicos, abertos, expostos e compartilhados. Embora nem sempre sejam percebidas, os topônimos presentes nos espaços públicos criam a paisagem, coadunando-se à linguística, buscando esclarecer o recorte de um lugar (TRAPERO, 1997).

Ao observarmos a linguagem que nos cerca, percebemos que essa paisagem é de suma importância já que, a partir dela, analisamos as nuances e os entrelaçamentos das práticas e políticas linguísticas que as edificam. Shohamy (2006) explica que as mudanças nas sociedades têm provocado mudança nas paisagens linguísticas das cidades e, dessa forma, entende-se que as escolhas linguísticas que as compõem não são neutras ou arbitrárias, mas revestem-se de valores simbólicos e de processos de semiotização.

Para a análise toponímica, escolheu-se um trecho composto por onze ruas dentro do centro histórico. A escolha deu-se ao fato de ser um local com considerável número de estabelecimentos e por ser frequentado por centenas de trabalhadores, e turistas. Além disso, o local é frequentado por docentes e discentes de campi universitários, federal e estadual, cujos prédios encontram-se em algumas das edificações tombadas pelo IPHAN (Instituto do Patrimônio Histórico e Artístico Nacional). Acresce-se a esses motivos, a alta frequência de pessoas que ali circulam uma vez que esse centro é local de órgãos públicos, pousadas, restaurantes, museus, casas residenciais, comércios, dentre outros.

Nessa conjuntura, este artigo, alicerçado no campo da paisagem linguística e circunscrito à área da Linguística Aplicada e Estudos da Linguagem, tem por finalidade 
analisar os usos de estrangeirismos nas paisagens linguísticas das seguintes localidades: Rua Portugal, Ladeira do Comércio, Rua da Feira Praia Grande, Rua Nazareth, Rua Djalma Dutra, Rua da Estrela, Travessa Marcelino Almeida, Rua do Giz, Rua da Palma, Rua Humberto de Campos e Avenida Dom Pedro II, que fazem parte de vasto acervo de pontos comerciais no centro histórico da ilha de São Luís.

\section{Fundamentação teórica}

A comunicação linguística se dá por textos. E texto pode ser entendido como uma estrutura inacabada, podendo "ser concebido como resultado parcial de nossa atividade comunicativa, que compreende processos, operações e estratégias que têm lugar na mente humana, e que são postos em ação em situações concretas de interação social” (KOCH, 1997, p. 26). Beaugrande (apud Marcuschi, 2008, p. 72), afirma que "o texto é um evento comunicativo em que convergem ações linguísticas sociais e cognitivas". Dessa forma, todo "texto é a expressão de algum propósito comunicativo. Assim, caracteriza-se como uma atividade eminentemente funcional, no sentido de que a ele recorremos com uma finalidade, com um objetivo específico, nem que seja, simplesmente, para não ficarmos calados" (ANTUNES, 2010, p. 30-31). Além disso, o "texto é a linguagem em funcionamento em contexto; (...) então texto é o processo de fazer significados em contexto" (HALLIDAY; MATTHIESSEN, 2014, p. 3) e por ser construído de significados, o texto é também uma unidade semântica (HALLIDAY, 2014).

Em relação à leitura, embora constituída em uma atividade cognitiva associada à compreensão textual, ela já foi equivocadamente conceituada como simples ato de decodificar signos linguísticos ou como extração de conteúdos que concedia predomínio a uma reprodução mecânica de informações ou identificação de sentidos. Entende-se, hoje, a leitura como um processo ativo de compreensão que exige do leitor uma posição ativa na análise dos textos.

O conhecimento prévio do leitor adquire um notável espaço no processo de leitura, uma vez que "o que o leitor traz para o texto é normalmente mais importante que o que ele acha no texto" (GRELLET, 2003, p. 7).

A concepção que predomina nos estudos atuais de leitura, segundo Kleiman (2004) é a de prática social, ligadas à situação, onde o contexto deve ser considerado para se fazer leitura adequada às circunstâncias. A leitura como prática social é 
subsidiada, na linguística aplicada, teoricamente pelos estudos do letramento. Nessa perspectiva, os usos da leitura estão ligados à situação; são determinados pelas histórias dos participantes, pelas características da instituição que se encontram, pelo grau de formalidade ou informalidade da situação, pelo objetivo da atividade de leitura, diferindo segundo o grupo social. Tudo isso realça a diferença e a multiplicidade dos discursos que envolvem e constituem os sujeitos e que determinam esses diferentes modos de ler.

Nessa perspectiva, onde a prática social e o contexto devem ser considerados para se fazer leitura adequada, entende-se que "a língua é um fenômeno cultural, histórico, social e cognitivo que varia ao longo do tempo e de acordo com os falantes: ela se manifesta no seu funcionamento e é sensível ao contexto" (MARCUSCHI, 2008, p. 240).

Compreende-se que as características que envolvem a funcionalidade de um texto, bem como sua contextualização, ajudam a entender que os componentes da paisagem linguística estão dentro de um enquadramento social constituídos de significados pertinentes de análises "para se entender com aprofundamento o papel do espaço e do lugar e relação à linguagem” (BLOMMAERT, 2013, p.09).

No tocante à língua, ela "é um conjunto de representações simbólicas do mundo físico e do mundo mental que: (1) é compartilhado pelos membros de uma dada comunidade humana como recurso comunicativo; (2) serve para interação e integração sociocultural dos membros dessa comunidade" (BAGNO, 2014, p.22). Seguem elucidações relativas à paisagem linguística e a gênero discursivo.

No que concerne a imagem, esta pode passar a ter interpretações diversas a depender das escolhas de estruturas composicionais uma vez que suas características, expressões, cores, formato, dentre outros elementos imagéticos que a compõe intrinsecamente, podem mudar seu significado, segundo a explicação a seguir, de Kress e Van Leeuwen (2006, p. 2):

Assim como estruturas linguísticas, estruturas visuais apontam para interpretações particulares de experiência e formas de interação social. Significados pertencem à cultura, ao invés de modos semióticos específicos. $\mathrm{E}$ a maneira que os significados são delineados pelos diferentes modos semióticos, a maneira que algumas coisas, por exemplo, são 'ditas' visualmente ou verbalmente, outras somente visualmente, e outras apenas verbalmente, é também culturalmente e historicamente específico. [...] Mas mesmo quando nós podemos expressar o que parece ter o mesmo significado tanto na forma de imagem ou escrita ou fala, eles serão percebidos diferentemente. Como exemplo, o que é expresso na linguagem através da escolha entre diferentes classes de palavras e estruturas de 
oração, pode, na comunicação visual, ser expressa através da uma escolha de diferentes usos de cor ou diferente estruturas composicionais. E isto afetará o significado. Expressar algo verbalmente ou visualmente faz diferença. (grifos nossos)

Textos também podem conciliar combinação de elementos verbo imagéticos que podem conduzir a diversificadas direções de leituras por entre seus pontos composicionais, onde há caminhos que vão além da linearidade da esquerda para a direita e de cima para baixo, havendo modos diferentes em sua composição e é justamente "a composição do todo, a maneira pela qual os elementos representacionais e interativos são construídos para se relacionarem entre si, a maneira que eles se integram em um todo significativo" que dão sentido ao texto e "em outras palavras, onde os elementos (dos participantes e dos sintagmas que os conectam ente si e ao leitor) os dotam com valores de informações específicas relativas entre si" (KRESS; VAN LEEUWEN, 2006, p. 176).

Para seu funcionamento como sistema comunicativo, o visual deve servir vários requisitos comunicacionais e representativos e, amparados na gramática sistêmicofuncional, Kress e van Leeuwen (2006) propõem que o visual se organiza em metafunções. A noção teórica das metafunções pode ser entendida como os usos que fazemos da linguagem (KRESS; VAN LEEUWEN, 2006) sendo que elas fazem parte do estrato semântico da linguagem, entendidas como os usos de que se faz dela. Em se tratando da metafunção composicional, esta está relacionada aos significados interativos e representacionais da imagem por três sistemas interrelacionados: o valor de informação, a saliência e o enquadramento. $O$ valor de informação pode ser identificado de acordo com as principais regiões da imagem como esquerda/direita, superior/inferior, centro/margem. A saliência pode ser identificada como os elementos que atraem a atenção do leitor para diferentes graus, pelos fatores de localização no primeiro plano ou no plano de fundo, tamanho relativo, contrastes em tonalidades, cores, nitidez etc. $O$ enquadramento está relacionado a elementos que criam linhas divisórias ou por linhas reais de quadros, conectando ou desconectando elementos da imagem (KRESS; VAN LEEUWEN, 2006).

\section{Paisagem Linguística}


Em um contexto repleto de singularidades históricas, a capital São Luís é a única cidade brasileira fundada por franceses, invadida por holandeses e, por fim, colonizada por portugueses. Nas ruas do centro histórico dessa cidade que detém o título de Patrimônio Mundial da Humanidade, concedido pela UNESCO, e com edificações tombadas pelo IPHAN, indaga-se sobre a disposição da paisagem linguística.

Landry e Bourhis (1997, p. 25) se referem a paisagem linguística como à "visibilidade e proeminência das línguas em placas públicas e comerciais em um dado território ou região", os autores trazem alguns exemplos do que consiste na paisagem linguística afirmando ser:

A língua de placas de trânsito, propagandas em outdoors, nomes de ruas nomes de lugares, placas comerciais e placas em prédios públicos juntos formam a paisagem linguística de um dado território, região ou aglomeração urbana. A paisagem linguística de um território pode servir duas funções básicas: uma informação funcional e uma função simbólica. (LANDRY; BOURHIS, 1997, p.25).

Paisagem linguística é também definida como "objetos linguísticos que marcam o espaço público" (BEN-RAPHAEL et al., 2006, p. 3); estes autores explicam ainda que esses objetos não devem ser confundidos com textos presentes em carros ou ônibus que estejam passando pelo local. Os autores salientam ainda que a paisagem pode mudar e um exemplo são os pôsteres que podem ser removidos ou fixados, dia após dia, enquanto outros tipos de placas podem permanecer por anos. Backhaus (apud BEN-RAPHAEL et al., 2006, p. 3) define sua pesquisa à análise de "qualquer texto dentro de um frame espacial definível".

Um aspecto inerente à paisagem linguística é que ela é um fenômeno majoritariamente urbano, além do fato de ter frequentes amálgamas de diferentes línguas (GORTER, 2006) que, neste caso, podem receber a alcunha de híbridos quando são formados por dois ou mais idiomas. Bakhtin (2010, p. 110), ao discorrer sobre construções híbridas, expõe que:

O enunciado que, segundo índices gramaticais (sintáticos) e composicionais, pertence a um único falante, mas onde, na realidade, estão confundidos dois enunciados, dois modos de falar, dois estilos, duas "linguagens", duas perspectivas semânticas e axiológicas. Repetimos que entre esses enunciados, estilos, linguagens, perspectivas, não há nenhuma fronteira formal, composicional e sintática: a divisão das vozes e das linguagens ocorre nos limites de um único conjunto sintático, frequentemente nos limites de uma proposição simples, frequentemente também, um mesmo discurso pertence simultaneamente às duas línguas, às duas perspectivas que se cruzam numa 
construção híbrida, e, por conseguinte, têm dois sentidos divergentes, dois tons.

Entende-se que, a partir das explanações acima, o hibridismo presente na paisagem linguística analisada nesta pesquisa pode fornecer informações sobre as crenças e influências linguísticas dos proprietários dos estabelecimentos que se utilizaram do mesmo para compor suas propriedades.

\section{Toponímia}

A linguagem que está visível ao público, juntamente com o estudo da paisagem linguística leva à necessidade de se pensar sobre a toponímia, que é "um complexo línguo-cultural, em que os dados das demais ciências se interseccionam necessariamente e, não, exclusivamente" (DICK apud ISQUERDO, 2019, p. 9). Além de nuances interdisciplinares, o estudo da paisagem linguística requer a serventia da toponímia, que pode ser assim clarificada:

A Toponímia é uma disciplina cuja problemática se integra à Linguística, à Geografia, à História, à Botânica, à Arqueologia, à Antropologia (...) E todas reivindicando um direito de propriedade. Mas temos que concordar que mais direito (não exclusivamente) que todas as outras tem a Linguística, como uma perspectiva que busca explicar uma parcela do léxico de um lugar, de uma região, de uma língua (TRAPERO, 1997, p. 1).

Ressalta-se que uma das características da paisagem linguística é abranger tanto os objetos linguísticos públicos da esfera municipal, por exemplo, como uma placa de identificação de atrativo turístico ou como uma placa de indicação, quanto os privados. Estes podendo remeter-se a estabelecimentos privados, por mais que devam ser regulamentados pelo poder público.

\section{Gênero Discursivo}

Todo texto e toda comunicação se realizam em algum gênero discursivo que tem suas peculiaridades e maneiras singulares de compreensão e leitura, e sua concepção consiste em "cada enunciado particular é individual, mas cada campo de utilização da língua elabora seus tipos relativamente estáveis de enunciados, os quais denominamos gêneros do discurso" (BAKHTIN, 2011, p.262). O autor reflete sobre a 
riqueza, diversidade e infinidade dos gêneros do discurso, afirmando que mesmo sem suspeitar da existência deles o discurso é moldado pelos gêneros em uso, que são dados "quase da mesma forma com que nos é dada a língua materna, a qual dominamos livremente até começarmos o estudo da gramática" (BAKHTIN, 2011, p. 282), sendo a língua, desta forma, uma prática social. Esta pesquisa requer explanações acerca dos gêneros identificados na paisagem linguística pesquisada.

Em relação ao gênero placa, Costa (2018, p. 191) explica que:

\begin{abstract}
Assim como o outdoor, o cartaz, ou o painel, a placa é um suporte, com formato de tabuleta, geralmente em bronze, mármore, granito, metal, ou outro material, que pode trazer uma inscrição comemorativa, uma propaganda, uma homenagem (placa de rua), etc. Pode ser também uma chapa que, emitida pela administração pública, representa sinal oficial de concessão de certas licenças e autorizações (...). Por extensão de sentido, placa passa a constituir um gênero escrito quando se refere aos textos comemorativos de propaganda ou de qualquer dessas licenças ou autorizações, geralmente curtos e objetivos. (grifos nossos)
\end{abstract}

Segundo Shohamy (2006), as placas podem ser divididas em: top-down, aquelas distribuídas pelo Estado, como nomes de ruas ou placas de sinalização; e as bottom-up, as de baixo para cima, ou seja, as distribuídas por pessoas privadas, como as relativas a estabelecimentos comerciais, anúncios particulares, anúncios publicitários, dentre outros. Essas duas categorias serão objetos de análise.

A placa de identificação, conforme a própria nomenclatura, serve para identificar o posicionamento no deslocamento com informações como destino e distância; as de identificação de atrativo turístico costumam indicar a localização desses atrativos com direção e pontos de interesse.

Entende-se que uma vez que o levantamento imagético da pesquisa também resultou de cartazes, faz-se pertinente a explanação desse gênero que, para Costa (2018, p. 66), é:

(...) anúncio ou aviso de dimensões variadas, muitas vezes ilustrado com desenhos ou com fotografias, apropriado para ser afixado em lugares públicos. Apresenta coerções genéricas semelhantes às de um outdoor, porém, geralmente, é de dimensão menor."

Já o banner se caracteriza por ser uma peça publicitária "por meio do qual se divulga algo ao público, ou seja, a criação de alguma mensagem de propaganda com 
objetivos comerciais, institucionais, políticos, culturais, religiosos, etc." (COSTA, 2018, p. 66).

Já o gênero mapa utiliza-se de linguagem técnica própria, comumente verbovisual que pode ser uma "representação gráfica e convencional, em papel, cartolina, tela, etc., dos dados referentes à superfície do globo terrestre, a uma região dessa superfície." (COSTA, 2018, p. 167).

\section{Análise dos dados de pesquisa}

A análise não randômica desta pesquisa abrange os usos de estrangeirismos localizados na paisagem linguística no centro histórico de São Luís, a saber, ruas atrativas na parte turística da cidade que englobam: Rua Portugal, Ladeira do Comércio, Rua da Feira Praia Grande, Rua Nazareth, Rua Djalma Dutra, Rua da Estrela, Travessa Marcelino Almeida, Rua do Giz, Rua da Palma, Rua Humberto de Campos e Avenida Dom Pedro II.

Enfatiza-se que esse tipo de pesquisa configura uma perspectiva que intenta:

(...) compreender o multilinguíssimo urbano e a diversidade linguística e, por essa razão, os dados não são destinados a indicar a composição linguística da cidade como um todo, mas uma simples ilustração da série de diversidade linguística presente na cidade ou em uma parte dela" (CLEMENTE et al, 2013, p. 120).

Em relação ao procedimento de coleta de dados, uma análise prévia foi feita nas ruas mencionadas para os apontamentos top-down e bottom-up (SHOHAMY, 2006). Registros fotográficos foram realizados quando se tratava de língua estrangeira. Mediante os procedimentos adotados nesta pesquisa, observaram-se setenta e quatro amostras no recorte da paisagem linguística constatada. Aponta-se que aproximadamente $85 \%$ das placas são do tipo top-down, enquanto aproximadamente $15 \%$ são as do tipo bottom-up.

Pequenas entrevistas informais com alguns donos e funcionários presentes dos estabelecimentos comerciais analisados também foram feitas com o propósito de averiguar a sua justificativa perante o uso de estrangeirismos. As pequenas entrevistas tinham como foco principal a motivação da escolha do nome dos estabelecimentos. Apesar de alguns proprietários não estarem presentes e seus 
funcionários demostrarem não saber o motivo da escolha, houve alguns informantes que responderam ao questionamento, conforme será demostrado a seguir. Ressaltase que algumas frases ditas pelos entrevistados estão entre aspas em nome da fidelidade do que foi dito por eles.

Em um dos estabelecimentos, cujo nome é em língua inglesa, foi informado que fora feita uma pesquisa com nomes que pudessem fazer jus à loja e que "tinha que ser internacional, já que várias empresas fazem dessa forma, como a Häagen-Dazs ou a Ben \& Jerry's". Neste estabelecimento, também foi informado que o nome em língua estrangeira soaria melhor que o português, e que muitos turistas preferiam locais em que eram atendidos em língua inglesa, subentendendo-se que o local tem atendimento conforme a língua da placa. Outrossim observa-se o anseio de identificarse com grandes marcas internacionais e globalizadas. Do ponto de vista imagético da placa tem-se um sorvete representado com a cor azul, acima do nome da sorveteria, Mr Cold, que, fazendo alusão ao produto ofertado, azul faz referência ao frio, gelado (KRESS; VAN LEEUWEN, 2006, p. 235), que também vem a ser a tradução do nome do estabelecimento.

Em um outro estabelecimento, cuja placa anunciava em português, inglês e francês, foi informado, pelo proprietário, que o estrangeiro "olha e entende que tem algo para ele. O acréscimo da língua francesa visa chamar a atenção do turista francês e o do inglês porque é língua de comunicação". A respeito da placa trilíngue, um recepcionista de outro estabelecimento, informou que recebem muitos turistas da Europa e dos Estados Unidos.

Um dos poucos estabelecimentos que se conseguiu entrevista diretamente com o proprietário foi um pub chamado The Black Cat Pub. Foi informado que o proprietário queria um nome forte para o estabelecimento, que é um bar temático alusivo a bruxas, e que combinaria com um gato preto, mas que o nome não cairia tão bem caso fosse em língua portuguesa, mas sim em língua inglesa. Reflete-se que os limbos entre as fronteiras linguísticas parecem se esvair, o que outorga tanto a noção de status quando a de fidúcia que são atribuídos à língua inglesa. Segue o registro da placa do pub abaixo:

Figura 1 - Nome do estabelecimento em inglês 
A pesquisa obteve algumas respostas sobre a explanação dos topônimos de forma um tanto inusitadas e destacam-se duas delas. Em uma loja cuja fachada tinha escrito Arts, questionou-se o motivo de tal escolha e foi informado que a dona não tinha conhecimento que estava em língua inglesa e que estava escrito daquela forma e não "Arte" porque ela não gostava da vogal "e". Em outra loja, após o questionamento do porquê da utilização do nome em inglês Art', foi informado que não estava escrito em outra língua a não ser a portuguesa. O que levou a pesquisadora a gentilmente requisitar que a informante fosse até a porta da loja e visse a placa e, após visualizá-la, a resposta que se obteve foi que o que estava escrito na foto em nada dizia respeito com a língua inglesa, pois, nas palavras dela (ipsis litteris) "o nome Art' está em português. O apóstrofo serve para substituir a letra "e", de acordo com a gramática portuguesa".

Após essas explanações reflete-se sobre as crenças que norteiam esses topônimos comerciais. Em uma reflexão envolvendo sociolinguística, ao tratar sobre língua, Blommaert (2010, p.28), explica que:

as pessoas fazem diferentes investimentos que atribuem diferentes valores $\mathrm{e}$ graus de utilidade. No contexto de globalização, onde as formas da língua têm mais mobilidade que antes, os padrões de valores e usos se tornam menos previsível e presumível.

Nessa conjuntura, as escolhas linguísticas, por mais que irrefletidas, carregam ideologias, representatividades e até relações de poder, mesmo que, presumivelmente, sem o real entendimento dos usos dos estrangeirismos.

Enquanto algumas respostas se destacam pelas suas peculiaridades informativas advindas de falas que requerem um tanto de ponderações, outras foram 
simples como ao se indagar sobre o porquê de o nome de um restaurante estar em italiano e ter como resposta que está em nesta língua pois o dono é italiano.

Frisa-se ainda que foram encontrados dois registros em língua espanhola nas ruas pesquisadas, sendo que um deles foi em um estabelecimento hoteleiro cujo texto era composto de quatro línguas: portuguesa, inglesa, francesa e espanhola. O outro que se obteve em espanhol foi uma pichação que se considera uma vandalização por ter sido feito na parede de um casarão tombado e, apesar disto, considera-se que este dado faça parte da paisagem linguística do centro histórico no período que a pesquisa foi realizada apesar de ser considerado crime no ordenamento jurídico brasileiro, de acordo com a lei 9.605/98, artigo 65 e incisos.

Com esta pesquisa observou-se que os estrangeirismos dispostos na paisagem linguística analisada a partir de registros fotográficos foi conforme a seguir:

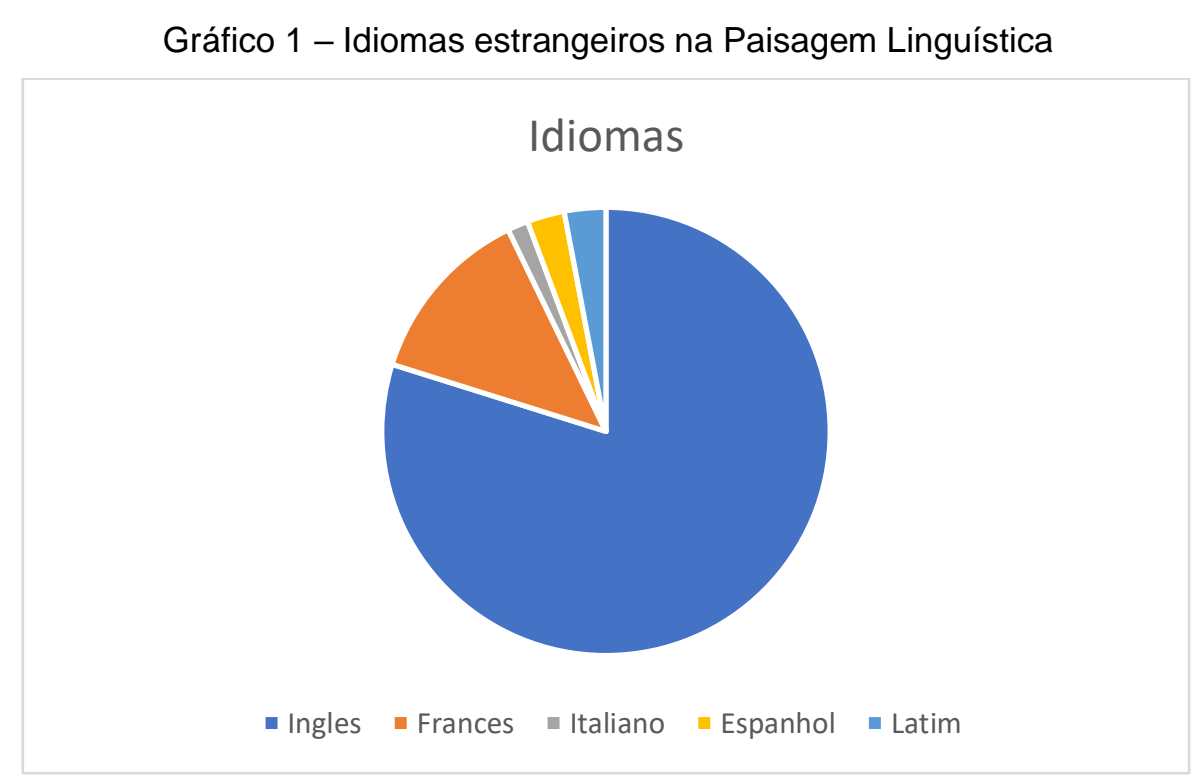

Fonte: Os pesquisadores (2021)

O gráfico acima retrata os idiomas estrangeiros utilizados nos topônimos na área que coube a esta pesquisa no centro histórico de São Luís. Com os dados obtidos, pode-se verificar que a língua inglesa estava presente em aproximadamente $80 \%$ (oitenta porcento) dos estrangeirismos. Entende-se este fato uma vez que essa língua tem o status de língua franca e língua global, sendo amplamente utilizada nas diversas amálgamas da comunicação, da ciência, da tecnologia, da cultura popular, da globalização etc. A língua francesa estava presente em aproximadamente 13\% (treze porcento) dos dados coletados, sendo a segunda língua estrangeira com maior 
aparição, enquanto a espanhola e a latina obtiveram dois achados cada e a língua italiana obteve um achado.

Na sequência, alguns dos registros dos estrangeirismos utilizados na paisagem linguística.

Figura 03 - Nome de estabelecimento em italiano

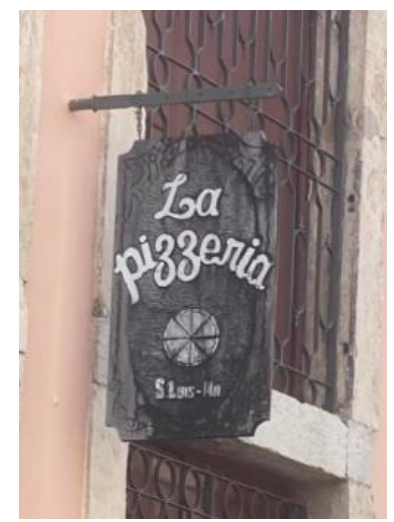

Fonte: Os pesquisadores (2021)

Figura 04 - Nome de estabelecimento em latim

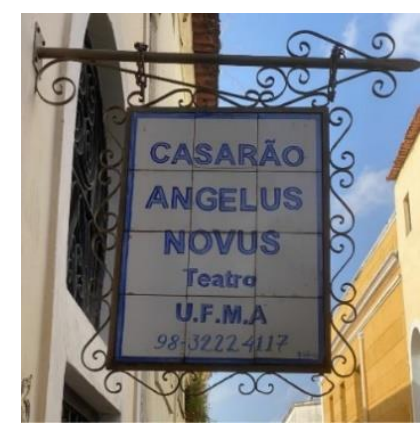

Fonte: Os pesquisadores (2021)

Figura 05 - Placa multilíngue

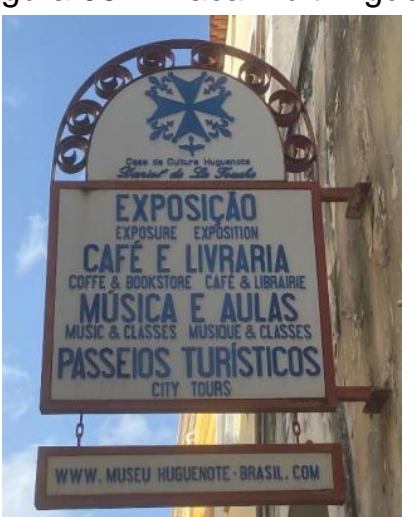

Fonte: Os pesquisadores (2021) 
Em relação ao hibridismo, obteve-se dois resultados e, a seguir, um exemplo de hibridismo:

Figura 06 - exemplo de hibridismo

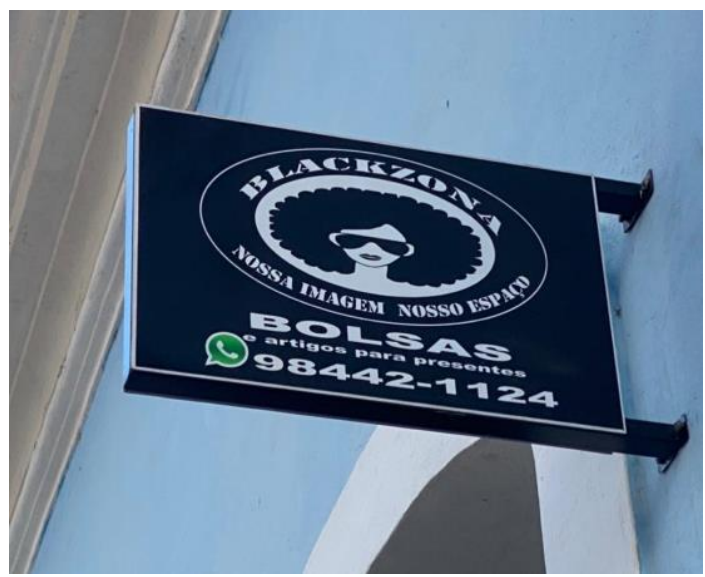

Fonte: Os pesquisadores (2021)

A placa acima revela que há duas línguas envolvidas: a inglesa e a portuguesa. Na leitura da palavra Blackzona, tem-se um neologismo híbrido formado por black, adjetivo em língua inglesa e de zona, que é um sufixo em língua portuguesa com características de aumentativo, comumente também utilizado informalmente. Esta placa representa um cunho semiótico, e não linguístico uma vez que o "importante não era a função linguística como signo denotacional, mas a função emblemática que tinha em destacar um complexo de significados associativos" (BLOMMAERT, 2010, p. 29), com as línguas vistas não como uma dicotomia, mas como uma complementaridade, demonstrando a dinamicidade da língua. Para uma melhor compreensão da placa, faz-se necessário a utilização do valor de informação. Ao se fazer a leitura da placa do estabelecimento, tem-se, no centro do texto visual, a representação de cabelos que remetem ao termo black, em uma composição central, um elemento da imagem que o leitor deve voltar atenção em particular (KRESS; VAN LEEUWEN, 2006).

As placas de indicação de atrativo turístico, estilo top-down, encontradas na extensão da pesquisa que contêm língua estrangeira estavam com língua inglesa e língua portuguesa, conforme exemplo da figura 06 a seguir, com exceção de um mapa, figura 08, que foi detectado na esquina da rua do Giz com a rua Nazareth, que estava em língua inglesa, portuguesa e francesa. Na sequência, seguem as figuras mencionadas: 
Figura 07 - Exemplo de placa top-down inglês e português

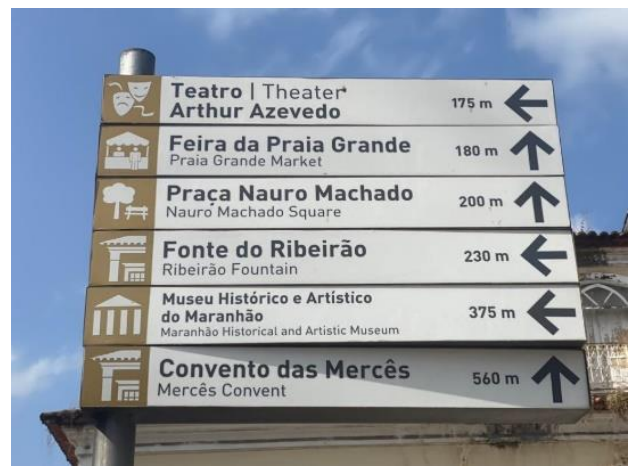

Fonte: Os pesquisadores (2021)

Figura 08 - Mapa trilíngue

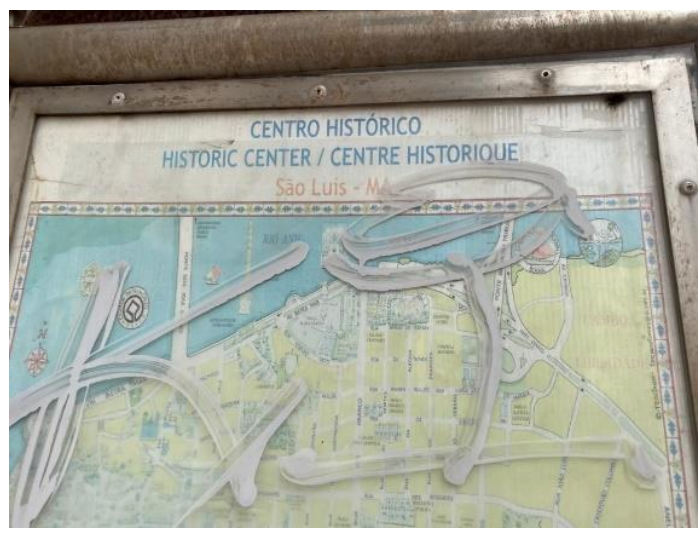

Fonte: Os pesquisadores (2021)

A pesquisa identificou em um estabelecimento o emprego de marcação de posse em língua inglesa, que é o apostrofo seguido da letra "s", mas que, nesse caso, a partir das imagens, possivelmente se referem ao plural dos substantivos que são vendidos na loja. Entende-se que não se trata de uma marcação de posse no banner quando está escrito que o estabelecimento tem "Cd's e DVD's" ou no próprio nome do estabelecimento que é presumivelmente o nome de um homem e o produto oferecido por ele. Segue a imagem:

Figura 09 - Marcação de posse

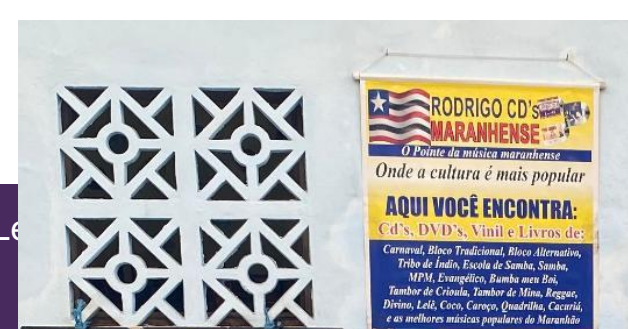


Fonte: Os pesquisadores (2021)

\section{Considerações finais}

Nesta pesquisa, buscou-se identificar os topônimos em língua estrangeira no espaço público da paisagem linguística de parte do centro histórico da cidade de São Luís. Ficou evidente que o uso da língua inglesa, com aproximadamente oitenta e oito porcento dos casos, é a predominante nas fachadas de estabelecimentos e em placas top-down e bottom-up, seguidas da língua francesa, língua espanhola e italiana. E, como a maioria das placas identificadas foram as do tipo bottom-up em língua inglesa, entende-se que o turismo contribui para certas escolhas, por se tratar de uma área turística, bem como conforme explanação de alguns dos proprietários dos estabelecimentos.

Ainda a respeito das crenças dos proprietários e/ou funcionários, é de suma importância frisar que não foi possível entrevistar cada um dos proprietários ou funcionários dos estabelecimentos comerciais, em virtude do contexto pandêmico que esta pesquisa foi realizada e, conjuntamente, muitos estabelecimentos se encontravam fechados; além do fato que alguns informantes das pequenas entrevistas desconheciam o porquê do topônimo escolhido. Lembrando que "não existe um uso significativo da língua fora das inter-relações pessoais e sociais situadas" (MARCUSCHI, 2008, p. 23).

Acredita-se que esta pesquisa represente uma contribuição no campo da paisagem linguística em uma cidade com características tão peculiares. Considera-se que mais pesquisas que envolvam este tema possam ser desenvolvidas, lembrando que as paisagens são mutáveis e podem depender inclusive de políticas linguísticas.

\section{Referências}

ANTUNES, I. Análise de Textos: fundamentos e práticas. São Paulo: Parábola, 2010. 
BAGNO, M. Língua, linguagem, linguística: pondo os pontos nos ii. São Paulo: Parábola, 2014.

BAKHTIN, M. Marxismo e Filosofia da Linguagem. São Paulo: Hucitec, 2009.

2010. Questões de literatura e de estética: a teoria do romance. São Paulo: Hucitec, . Estética da Criação Verbal. São Paulo: WMF Martins Fontes, 2011.

BEN-RAPHAEL, E. et al. Linguistic Landscape as Symbolic Construction of the Public Space: The Case of Israel. In: GORTER, D. Linguistic Landscape: a new approach to multilingualism. Londres: Routledge, 2009.

BLOMMAERT, J. Ethnography, Superdiversity and Linguistic Landscape: chronicles of complexity. Bristol: Short Run Press, 2013.

2010.

. The Sociolinguistics of Globalization. Nova York: Cambridge University Press,

COSTA, S. Dicionário de Gêneros Textuais. Belo Horizonte: Autêntica, 2018.

HALLIDAY, M.; MATTHIESSEN, C. Halliday's Introduction to Functional Grammar. Abingdon: Routledge, 2014.

HASAN, R. Part B. In: HALLIDAY, M.A.K.; HASAN, R. Language, context, and text: aspects of language in a social-semiotic perspective. Oxford: Oxford University Press, 1989.

ISQUERDO, A. (org). Toponímia ATEMS: caminhos metodológicos. Campo Grande: UFMS, 2019.

KRESS, G.; VAN LEEUWEN, T. Reading Images: The Grammar of Visual Design. New York: Routledge, 2006.

KOCH, I. O texto e a construção de sentidos. São Paulo: Contexto, 1997.

MARCUSCHI, L. Produção Textual: análise de gêneros e compreensão. São Paulo: Parábola, 2008.

SHOHAMY, E. Language Policy: hidden agendas and new approaches. Abingdon, Routledge, 2006.

TRAPERO, M. Contribuciones al estudio de la Lingüística Hispánica. Homenaje a Profesor Ramón Trujillo (ed. Manuel Almeida y Josefa Dorta). La Laguna: Montesinos y Cabildo Insular de Tenerife, vol. II, p. 241-253, 1997. 